\title{
Erratum: Reliable phase-contrast flow volume magnetic resonance measurements are feasible without adjustment of the velocity encoding parameter
}

\author{
Kerstin M. Lagerstrand,, a,b,* Frida Svensson, ${ }^{\text {a,b }}$ Christian L. Polte, ${ }^{c, d}$ \\ Odd Bech-Hanssen, ${ }^{c, d}$ Göran Starck, ${ }^{\text {a,b }}$ Artur Chodorowski, \\ and Åse A. Johnsson ${ }^{\text {a,f }}$ \\ ${ }^{a}$ University of Gothenburg, Institute of Clinical Sciences, The Sahlgrenska Academy, \\ Sweden \\ ${ }^{\mathrm{b}}$ Sahlgrenska University Hospital, Department of Medical Physics and Biomedical Engineering, \\ Gothenburg, Sweden \\ 'University of Gothenburg, Institute of Medicine, The Sahlgrenska Academy, Sweden \\ ${ }^{\mathrm{d}}$ Sahlgrenska University Hospital, Department of Clinical Physiology, Gothenburg, Sweden \\ ${ }^{\mathrm{e}}$ Chalmers University of Technology, Department of Electrical Engineering, \\ Gothenburg, Sweden \\ ${ }^{\text {fS }}$ Sahlgrenska University Hospital, Department of Radiology, Gothenburg, Sweden
}

[DOI: 10.1117/1.JMI.8.6.069801]

This article [J. Med. Imag. 7(6), 063502 (2020) doi: https://doi.org/10.1117/1.JMI.7.6.063502] was originally published in Vol. 7, Issue 6 of the Journal of Medical Imaging (JMI) on 9 December 2020 with the incorrect spelling for the surname of the author Artur Chodorowski. The article was republished with the correct spelling for the surname on 13 November 2021.

\section{Disclosures}

The authors have no conflicts of interest to disclose.

*Address all correspondence to Kerstin M. Lagerstrand, kerstin.lagerstrand@vgregion.se 